\title{
To See a World in a Grain of Sand-The Transformative Potential of Small Community Actions
}

\author{
Atsushi Watabe ${ }^{1, *}$ and Simon Gilby ${ }^{2}$ \\ 1 Institute for Global Environmental Strategies, 2108-11 Kamiyamaguchi, Hayama, Kanagawa 240-0115, Japan \\ 2 Independent Researcher, London SE1, UK; simongilby@gmail.com \\ * Correspondence: watabe@iges.or.jp
}

Received: 6 August 2020; Accepted: 4 September 2020; Published: 9 September 2020

\begin{abstract}
The recognition of the urgent need for more sustainable lifestyles dates from the late 20th century, originating in concerns about resource depletion and climate change. Research and policy measures have evolved since then, paying increasing attention to systemic change over individual behaviour. However, as individual behavioural change is constrained by the systems within which choices are made, more study is needed to understand better how systemic changes occur. Drawing on the experiences of the Sustainable Lifestyles and Education Programme of the UN-led One-Planet Network in collaborating with small collective actions for sustainable lifestyles, the paper analyses the needs and approaches for sustainable lifestyles and opportunities for the local actors to grow their capacities in developing ways of living sustainably. These experiences show that the pursuit of sustainable lifestyles is not a one-shot change in behaviour. It is a continuous process where actors identify and tackle locally specific opportunities for responsible and sustainable ways of living, and through a process of mutual learning and experimentation gradually shape shared visions of sustainable living. Systemic changes for sustainable living are ultimately neither about simply improving people's awareness or attitudes or replacing some components of the external systems. They are the creation of capacities and aspirations of people actively and continuously engaging to shape alternative systems of living.
\end{abstract}

Keywords: sustainable lifestyles; collective actions; One-Planet Network

\section{Introduction}

Today, our global footprint is about one and a half times the Earth's total capacity to provide renewable and non-renewable resources to humanity. If nothing changes, in 35 years, with an increasing population that could reach 9.6 billion by 2050 , we will need almost three planets to sustain our ways of living. Rethinking the ways we produce, consume and exchange has become crucial to move towards a society where we can all live well within the boundaries of our planet [1].

For as long as the critical role of our lifestyles in ensuring the sustainability of the planet has been widely recognised, policymakers, practitioners and researchers have argued for the need for more sustainable lifestyles with such a statement [2-5]. Since the Sustainable Lifestyles and Education Programme of the One-Planet Network was launched in 2014, the programme's partners including the authors of this paper have also worked in-line with this thinking.

Although we believe that this thinking is still valid, by conceptualising sustainable lifestyles in such a way, we run the risk of narrowing down the scope to "environmentally friendly" individual behaviour [6,7] and ignoring the broad range of elements that constitute (un)sustainability of living [8-10]. In fact, during the past two decades, research focus has shifted from individual behavioural change to the changes in "systems" that shape the enabling and constraining contexts of 
lifestyles [11-14], or the entangled elements that shape the possibilities and limitations of our ways of living $[15,16]$.

However, it is not easy to induce the changes to the systems that eventually enable the uptake of sustainable ways of living [11]. Indeed, we are not very clear about what we mean by "systemic changes", or the roles that actors in the society-either as individuals, members of organisations, or organisations-can play. This paper aims to contribute to the discussion of sustainable lifestyles through gaining a deeper understanding of the changes of "systems" that eventually propel the shift in lifestyles and draws on the lessons learned from the projects supported under the framework of the Sustainable Lifestyles and Education Programme (SLE Programme) of the UN 10-Year Framework of Programmes on Sustainable Consumption and Production Patterns (One-Planet Network). The next section looks into the shifting research focus on lifestyles in association with the common trap of individual focus and increasing attention to collective actions, followed by the introduction of the SLE Programme. The third section looks at the materials and methods used by the projects. The fourth section reflects on the critical lessons of ground-level collective efforts supported under the SLE Programme, paying attention to the challenges these initiatives addressed, approaches adopted to address these challenges, and reflections on lessons learned. Based on these reflections, the final section discusses the meaning of "systemic change" at the day-to-day level.

\section{Sustainable Lifestyles and Increasing Attention to Collective Actions}

\subsection{Lifestyles-Allure into the Diagnostic Point of View}

The sharp increase in the use of natural resources in association with an ever-increasing demand for goods and services has created significant pressure on the natural environment and the planet as a whole. The issue has become more and more pressing throughout the late twentieth century and early twenty-first century, due to the rapid economic development and continued population growth in emerging economies, resulting in the urbanisation and emergence of the new middle class. Against this backdrop, dominant arguments on sustainable lifestyles have focused on the negative impacts of our lifestyles. Mass-consumption lifestyles have been fingered as the cause of the unsustainable and severe damage to the environment by bringing about ever-increasing use of natural resources, greenhouse gas emissions, and waste and pollution [17]. Our society needs to achieve decoupling of resource use and economic growth or natural resource use and human wellbeing in this context $[18,19]$. Having taken this consideration as a starting point, the literature on sustainable lifestyles or living have generally referred "to using as few resources as possible, reducing carbon footprints, and reducing environmental damage" [10]. It has often been taken as a term interchangeable with sustainable consumption [20] though some have called attention to the fact that lifestyle is far broader than consumption [21]. However, such focus on the "negative impact of consumer behaviour on the sustainability of the environment" has made us incapable of capturing how lifestyles, entangled with broader elements of the society, would continue or change. Here, it is worth looking back on how the concept of lifestyles has been used in much wider contexts than environmental sustainability.

The concept of lifestyles has been developed gradually within social science since the nineteenth-century, with significant contributions being made, inter alia, by Thorstein Veblen (on conspicuous consumption of goods and leisure activities), Georg Simmel (on the dynamics of styles through trickle-down emulation in the modern urban life), and Max Weber (on the stratification of relationships based on styles rather than position in the labour market). Sociologists have used the concept to capture the dynamics of classification in modern societies through differentiation and emulation [22]. Such earlier concepts have been elaborated by Bourdieu clarifying the differences of social, economic and cultural capitals among people in different positions in the social hierarchy [23]. In the late twentieth century, against the backdrop of the flattering of the social forms and the instability of the modern forms of social membership [24], sociologists deepened the analysis of lifestyles as the process of reflexive self-identification, arguing that people express their personal views of their (ideal) 
position in society through their consumer behaviour, products and services they acquire and the ways they organise their time through using them [25]. However, empirical research also supports the remaining validity of class [26-29].

Many fields of science have adapted lifestyles as a key concept. For instance, health care science has identified many lifestyle diseases such as cardiovascular diseases (CVDs), stroke, diabetes and certain forms of cancer. Their risks are heavily associated with the individual patterns of actions, such as diet, smoking and physical exercise [30,31]. Marketing research has traced the changes and stratifications of consumer lifestyles by analysing the changing trends of expenditures [32-34]. It is important to note that many of these different streams of lifestyle studies share an angle: a lifestyle, understood as the pattern of individual (or group) actions, needs to be studied to address the background/direct cause of specific status of the present society. Such a diagnostic angle is valid as long as it tries to pin down the causes of modern challenges. However, it inevitably narrows down the objectives and outputs of the studies toward producing practical measures for intervening in the single behaviours performed by individuals. Spaargaren and Oosterveer warned that "lifestyle politics could mistakenly be interpreted as dealing with 'individual' human beings and their private, individual affairs primarily and exclusively" [12]. Such an angle is narrow compared to the arguments that lifestyles are not single behaviours based on the free choice of individuals, but collective constructs and social constructions that groups of people (ethnic groups, subculture groups, etc.) develop and change dynamically over time [22]. Evans and Jackson also pointed out that lifestyles as self-identification are not personal processes but "tensions between individual and collective identities" [21].

The mainstream sustainable lifestyles discourse seems to have been taken over by this narrow scope. For several reasons, this has caused difficulty in understanding how changes in lifestyles occur, and effectively inducing desirable changes. Firstly, they often pay attention to a limited range of "environmentally sustainable" actions (e.g., buycotting, boycotting ethical consumption, voluntary simplicity) in specific domains (e.g., water, food, energy, consumer goods) [9]. Because of this narrow focus, they tend to avert their eyes away from the uncomfortable fact that a significant part of our daily practices has become more and more resource-intensive [6,7]. Secondly, framing lifestyles solely as individual actions and behaviour misleads one into the well-known "mystery" of the attitude-behaviour gap [35-38]. This concept is described as when people, despite having abundant knowledge of the negative consequences of their behaviours as well as clear intentions to reduce their impacts, do not adopt such "sustainable" practices in reality [35,39,40].

\subsection{Lifestyles-As a Dynamic Web of Practices}

However, the gap is not a mystery. The difficulty in interpreting the gap comes from the assumption that an individual is considered to have a portfolio of values, attitudes, norms, interests and desires, and selects from them to decide on the course of action [41]. However, research has shown that such a linear assumption of attitude, behaviour and choice (ABC) is overly simplistic [42]. Practice theory offers a deeper understanding of the complex nature of inertia or changes of behaviours [43-48]. The concept of practices, originating from the earlier sociologists such as Bourdieu and Giddens, have evolved since the 1990s with particular attention to sustainable consumption. Practice comprises competence, meaning, materials, and the interplays among people, instead of the behaviours driven by the attitudes of individuals. According to practice theory, a new practice is formulated and spread in association with the changes in the systems of provision [11-14,21], or is shaped through the transfer of the competence, meaning, or materials from existing practices to another $[49,50]$. For instance, the spread of daily bathing was the result of the changes in the knowledge and belief on health, sanitation and appropriateness, as well as the development of the water system. Mobility patterns in urban areas not only change due to the implementation of a congestion tax, but also by the changing contexts of practices such as eating, learning and working [49].

In this perspective, people conduct actions in a web of many elements that force them to take multiple roles (e.g., consumers, family members, employees). Their actions are not conducted in a 
single domain but are closely linked to the needs and conditions of multiple domains (e.g., moving for shopping and working) $[9,14,41]$. Finally, in such a manner, behaviours and lifestyles are the constructs of collective/social interactions [22,41]. On this account, "the mystery" of the gaps between attitude and behaviours "arises from the failure of the portfolio model as a paradigm for human activity" [41]. What we observe as "changes in lifestyle" is often a superficial layer of the complex changes of the systems comprising a variety of elements that create and deliver specific values of goods or services benefiting our living, as well as the associated appropriation or abandonment of competence, meanings, and materials, shaped by the unique conditions on which individuals and groups of people are situated. For instance, it is often argued that people tend to change their behaviours at turning points in their lives. However, this conclusion has been challenged by other research as overlooking the fact that changes at turning "points" may take place over years, multiple changes in behaviours take place and influence each other, and the changes are often for the sake of meeting the needs of their families, instead of personal needs with further investigation needed to more fully understand how people transition through their lives [51]. Lifestyles often change without intention or clear design but through dynamic processes of bonding different elements into bricolage [52]. In sum, our lifestyles are organised as a part of the webs of diverse needs and competences in various domains, complex network of people, and contexts of technology and institutional settings. Researchers have proposed concepts to capture such complexity, e.g., "web of constraints" to look into the construct and constraint of practices through the changes in technology, social relations [15], systems of provision [14,20], and the prism of sustainable consumption covering the practice and the conditions and contexts of the economy and environment [53].

\subsection{Collective Actions on Lifestyles}

However, such focus on the systems or webs poses additional questions. How do systems change? How can we initiate changes in systems? In paying attention to systems, we are tempted to expect that powerful actors such as governments may replace a few of their vital parts to quickly change the entire systems and induce desirable changes of behavioural patterns. Such a view is not entirely untrue if we look back on some past cases, such as how the development of the subway network changed the mobility of the citizens. However, such an engineering point view keeps us in the trap of the narrower focus on the systemic causes of "environment-(un)friendly" behaviours of individuals. While lifestyles are shaped in the web of elements, we would need to pay attention to the changes of "relations between elements" rather than jumping on to the replacement of components through technical fixes. Moreover, given the radical alteration to our current systems required to enable sustainable ways of living, top-down approaches are insufficient in terms of the reductions required and ineffective when attempting to force people to adopt new ways of living without their full participation and consent. Such an approach would deprive people of opportunities for critically understanding the conditions and consequences of their ways of living, and, thus, may lead to backlash and failure.

Here, collaborative actions, including grassroots or micro-scale initiatives deserve attention [54-57]. Such initiatives are often carried out in protective spaces [58] where actors are relatively free from the ordinary constraints such as political/legal requirements, dominant actors of the market, and social norms that force them to follow business as usual. Through engaging in and driving the alternative actions and the enabling conditions thereof, people grow and exercise their capacities to create alternative contexts of living that enable them to live more sustainably [59-63]. Additionally, micro-scale collective actions have some features that may help us explore the key questions of this paper-how actors engage in systemic changes for sustainable lifestyles.

1. Collaborative actions take place in specific local settings where actual challenges of (un)sustainable living are dynamically shaped. All "unsustainability" issues take concrete forms in the particular contexts of certain spaces-rural, suburban or urban areas. For instance, in his argument on the role of the cities in shaping grassroots niches, Marc Wolfram [64] pointed out "the implications of the cities for the way in which citizens and local civil society actors get involved in the spatially 
embedded reproduction of socio-technical regimes and/or creation of sustainability innovations", referring to Bulkeley et al. and Baker et al. [65,66]. While unsustainability issues emerge at certain spaces, people also address them at specific sites, sometimes resulting in new forms of cooperative relations. For this reason, examination of collective initiatives opens up opportunities to learn how unsustainability challenges arise in the real contexts of specific spaces [67] as well as how individual/organisational capacities to address them are formulated and often unevenly distributed [54].

2. Facing the dynamics of (un)sustainability, collective actions may not be able to induce ground-level changes if they simply transfer existing knowledge or skills on "sustainable behaviours" to the "beneficiaries" who are assumed to lack them. Instead, knowledge and skills are co-created through the collaboration and mutual learning of the participants with different backgrounds [68], including the reshaping of the relations among them [54,62]. Interestingly, collective actions do not only help to build alternative relationships between human actors. The creation of new knowledge and skills often means that new relations are established between human and nonhumans constituting the web of practices through various forms of actions [69], for potentially changing their status in the global socioeconomic systems. Thus, we could learn from collective actions how such knowledge and relations are built in-between different elements and support the actors altering the current constraints of living.

3. Collaborative actions frequently do not go as planned in the real-world context. They face a variety of unforeseen challenges making actors review what steps they should carry out to achieve their goals. Sometimes they are urged to consider their objectives-what kind of lifestyles or societal contexts that they wish to make. In doing so, they attach meanings to the conditions they face-why the current conditions are unacceptable and what kind of alternative they want to create [59]. In other words, they do not only engage in the actions toward pre-set goals but participate in the transitions "in-the-making" where the issues, models of participation, and attending public are dynamically formed [70]. For such a reason, by looking at or participating in collective actions, we can learn how various actors learn from reality and dynamically shape their transitions.

In short, the (un)sustainability of lifestyles emerges and dynamically evolves in the locally specific contexts of living, knowledge of (un)sustainability and capacities to address it are formed in the dynamic relations among people and surrounding conditions and actors learn from reality and dynamically shape the transitions. We can tentatively posit that changes in the technical or institutional elements of the systems and changes in the intentions and competences of the people are adjacent and entangled with each other, and, thus, are not replaceable separately, and that systemic changes may not occur (only) through the replacement of elements to drive the current unsustainable living to the pre-defined sustainable living, but through the process in which actors engage in the reshaping of the webs. Further investigation into these points would, therefore, guide us in gaining a deeper understanding of what the changes of "systems of provisions" are or the entanglements shaping the contexts of living, and how people and organisations, as well as material elements, interact in guiding such changes. On such a consideration, the latter half of the paper takes a closer look at the three critical points for gaining insights on how actors initiate and engage in the systemic changes.

1. How did actors identify the locally specific challenges of (un)sustainable living?

2. How did actors create and share the knowledge and skills to address them?

3. How and what did actors learn to dynamically and continuously shape their transitions?

To this end, we draw on some of the ground-level collective actions that we have collaborated with or learned from under the SLE Programme. 


\section{Materials and Methods}

To gain the insights into the three critical points of the changes in systems or webs of elements shaping our lifestyles, the paper draws mainly on some of the projects that the SLE Programme has selected through open calls for project proposals and supported from 2016 to 2019. There was a total of four calls for project proposals from developing countries and countries with emerging economies that address unique challenges for (un)sustainable lifestyles and contribute to reducing greenhouse gas (GHG) emissions through their activities. The SLE Programme selected 24 projects in total. The SLE Programme has given financial assistance ranging from USD 50,000 to 400,000 depending on the proposals, utilising funds from the Government of Japan, as well as providing technical support covering procedural or contract issues, suggestions regarding activities and needed skills/capacity development or resource persons. Programme coordinators visited project sites as necessary for consultation and provided support as needed, for instance, negotiating with the local government or assisting with remedial action. A significant part of the information referred to in this paper was collected through such collaboration between the programme coordination desk and the project implementers.

In addition, the paper also refers to some of the ground-level initiatives which the SLE Programme studied through a scan of practices and policies for sustainable lifestyles during 2016-2017. More specifically, these cases were examined under the project entitled Envisioning Future Low-Carbon Lifestyles and Transitioning Instruments (2017-2019) that scanned transformational policies and ground-level initiatives globally through desk-based research and a call for case studies. The SLE Programme mostly learned from these ground-level initiatives through online interviews and also collaborated on a case study report published in 2019 [71]. Table 1 gives a summary of the open call for projects and scan of policies and instruments. See Appendix A for the list of projects and cases.

Table 1. Sustainable Lifestyles and Education (SLE) Programme's Open Call for Projects and Scan of Policies and Instruments.

\begin{tabular}{|c|c|c|}
\hline & Open Call for Projects & Scan of Policies and Instruments \\
\hline Selection & $\begin{array}{l}\text { Four open calls for projects (2016-2019 } \\
24 \text { projects selected out of more than } 600 \\
\text { proposals }\end{array}$ & $\begin{array}{l}\text { A call for case studies (2017) } \\
30 \text { cases of policies and civil society } \\
\text { initiatives identified out of } 120 \\
\text { submissions and desk-based research }\end{array}$ \\
\hline Main criteria & $\begin{array}{l}\text { Activities in developing countries and } \\
\text { countries with emerging economies } \\
\text { Completing in } 12 \text { to } 24 \text { months } \\
\text { Addressing local challenges for } \\
\text { sustainable lifestyles } \\
\text { Contribution to greenhouse gas (GHG) } \\
\text { emissions reduction }\end{array}$ & $\begin{array}{l}\text { Transformational policies and instruments } \\
\text { supporting pathways toward low-carbon } \\
\text { and sustainable lifestyles } \\
\text { Covering both developing and developed } \\
\text { countries }\end{array}$ \\
\hline SLE Programme's Collaboration & $\begin{array}{l}\text { Financial support (USD 50,000 to 400,000) } \\
\text { Online support (e.g., contract issues, } \\
\text { specific skills and knowledge, elaboration } \\
\text { of action plans, GHG monitoring) } \\
\text { On-site support (e.g., attending training } \\
\text { workshops, negotiation with local } \\
\text { stakeholders) }\end{array}$ & $\begin{array}{l}\text { Awarding of a few best cases } \\
\text { Online interviews to capture the detail of } \\
\text { the contexts, activities and outcomes } \\
\text { Publication of a case study report with the } \\
\text { implementers }\end{array}$ \\
\hline Information source & Online and on-site consultation & $\begin{array}{l}\text { Online interviews with project } \\
\text { implementers } \\
\text { Case study reports } \\
\text { Desk-based research including } \\
\text { peer-reviewed and grey literature }\end{array}$ \\
\hline
\end{tabular}


The authors of the paper were engaged in the process of selecting and supporting the projects. After the selection of the projects, they attempted to accompany the process of these projects in planning, implementing and monitoring, rather than conduct the summative evaluation with pre-designed criteria. This enabled the authors to elaborate the perspectives on the three critical points, i.e., (a) challenges of (un)sustainable living, (b) approaches taken to address the challenges and (c) learning obtained, through the collaboration and communication with the project implementers. The authors admit that a variety of conditions, such as the authors' positions as the programme coordinators, the capacities of the project implementing teams and the external conditions that affected the project implementation, made considerable influences of the following analysis. However, precisely because of such positions, the authors could come closer to the ground-level innovations in the making.

\section{Results: Ground-Level Collective Actions for Sustainable Lifestyles}

In what follows, we will look back on the challenges of sustainable living addressed, the approaches taken, and the insights obtained through collaboration with partners, based on the experience of our cooperation and communication with the projects.

\subsection{Challenges of (Un)Sustainable Living}

Twenty-four projects supported under the SLE Programme and 30 cases of initiatives we learned about through the call for submissions and desk-based research aimed at enabling sustainable lifestyles in one or more "domains" of living, such as energy consumption, water use, wasting and recycling, food production and consumption, housing (including heating and cooling houses), purchasing of consumer goods and livelihoods. However, we should pay attention to the fact that our behaviours and the surrounding contexts enabling and constraining them to comprise a mixture of conditions which cannot be separated into those "domains". On account of the crosscutting nature of lifestyles and the diversity of the purposes of the collective actions, we would need to pay more attention to the "why" of these actions. In other words, we would need to understand the challenges of the current patterns of living or the contexts associated.

All projects addressed the challenges of living or lifestyles which cause negative impacts on environmental sustainability. Among them, 17 of 24 projects dealt with the consequences caused by increased consumption and production in the context of rapid economic growth and urbanisation. This was not surprising considering the criteria of the calls for project proposals and case studies. The SLE Programme's calls for projects asked for submissions of proposals contributing to low-carbon lifestyles based on the local needs and opportunities. The call for case studies also requested the applicants address unsustainability issues in association with overconsumption. Projects thus aimed to reduce environmental impact through actions such as waste reduction and recycling, energy-saving and water-saving, more sustainable production of food or textiles and effective land management.

However, such negative impacts on the environment are not the only challenges for sustainable lifestyles. Even societies isolated from growth often suffer from negative environmental effects emerging in geographical, political or economic conditions. Furthermore, societies with economic growth, as well as those with a stagnant economy, may also suffer from a diversity of threats to stable livelihoods and consumption patterns. Many projects tried to create contexts of living whereby people could live more stable, secure lives, while at the same time mitigating negative environmental impacts. Detailed examples follow in the boxes below, starting with Box 1, which further illustrate the arguments made in this article. 
Box 1. Case 1: Empowerment of Armenian Rural Community with Solar Power.

A project based in Armenian rural communities dealt with saving electricity and gas use in families and public facilities. The project team worked with community leaders and local governments in introducing some simple tools for utilizing abundant solar power to support local lives. However, the primary issue was not increased environmental impacts, but the energy mix of the local society, which was dependent on imported gas. While household income is limited due to economic stagnation, a hike in gas prices has put financial pressure on households and various local organisations, including schools and kindergartens which were forced to shut down in the winter. Additionally, because rural highland areas get dark early in the evening, people were reluctant to go out and join social activities. This indicates that increasing energy costs posed a threat to socioeconomic opportunities.

The project, thus, planned to introduce solar cookers and dry-fruit makers to families to reduce energy cost, solar water-heaters at schools and kindergarten to support them to operate in the winter and solar streetlights to enable people to participate in social activities safely. The project, however, needed to make a couple of modifications to their activities of installing solar tools. They found that the solar cookers for households were not practical in the winter due to low temperatures. They gave up the plan and instead established a large solar dry-fruit maker at the women's centre. This allowed the community people to organise training sessions for villagers as well as people from the neighbouring areas. They also received requests from the parents of the kindergarten kids where they installed a solar water heater. The instalment of the water heater was originally intended to reduce operational costs so that the kindergarten can open longer in the winter. However, the parents asked if the project can set up a warm swimming pool using the heated water. In such a way, the cancellation of the solar cooker, and the changes in the purpose of using warm water, enabled the project team and the participants to explore a broader range of opportunities for utilizing the solar power in improving their living conditions than initially planned.

Additionally, the project's proposal to set up the solar-photovoltaic-powered streetlights was not favourably accepted by the local government in the beginning. In the male-dominated rural societies in Armenia, the village government did not trust the project team comprised only of women. However, the repeated visits enabled them to gradually gain a shared understanding of the challenges of the community-due to the high altitude of the area, even the central sections of the village become dark at $6 \mathrm{pm}$, making villagers feel unsafe participating in social activities. The local government suggested the streetlights be installed in the street in front of the village's community sports centre so that more villagers can come out. Moreover, the government promised to secure the budget to expand the lighting after the project period.

In short, challenges of unsustainable lifestyles comprise two issues, namely, (a) an increase in the negative impacts of our behaviours on the environment, economy and society, and (b) the destabilisation or vulnerability of our lifestyles due to changes in environmental, economic and social conditions. Efforts towards supporting the shift to more sustainable lifestyles encompass the pursuit of situations where people can adopt responsible living that minimise the negative outgoing impacts and a reliable living which provides people with the capacity to prepare for, withstand and recover from external shocks and stresses. Importantly, these two elements are interconnected with each other in several ways. First, specific economic conditions, namely the dependency on a high-cost energy source, endangered both household economies and health, as well as limiting their participation in essential services, thus, leading to the high impacts, are shown in a few cases such as Armenia. Second, instability of livelihoods makes it more difficult for the local people to choose alternative options for livelihoods or participate in collective actions to conserve and improve their natural environment. Third, increasing overconsumption or the sharp rise in demand for goods or services among specific groups in society often caused insecurity or instability for other vulnerable groups. For instance, the rapid growth of the tourism sector in Da Nang, Vietnam caused a sharp rise in water demand in coastal resort development zones (Box 2). This resulted in an increasingly unstable water supply for the residents living in inland areas. Both those who have lived in the city for many years and the newcomers who tend to live in the hilly zones are equally affected. 
Box 2. Case 2: Water-Smart Lifestyles in a Growing City of Vietnam.

A project in Vietnam worked on the increasing demand for water in the city of Da Nang. The expanding tourism sector in Da Nang has driven economic growth, as well as a construction boom in the seafront area, with other areas of the city also seeing a population influx. This has pushed water demand close to the limit of the current water supply system. As a result, a significant number of hotels have opened in coastal areas and require an enormous amount of water to provide services to their guests. This leap in water demand in the tourism sector destabilised the water supply to citizens, including those living in high-altitude areas. Furthermore, the increasing tendency of severe flooding and storms pushed the city to develop a more stable water system with both supply-side and demand-side measures.

The project organised a kick-off workshop in October 2017, inviting various participants concerned in the issue of water security. Many participants pointed out that it would be most useful to provide active learning programmes for younger children to support the families in changing water-using behaviours since families are positive in taking up new knowledge their children obtained. The project, thus, built a partnership with schools and kindergartens to prepare and conduct relevant programmes. Later on, the learning programmes evolved into a city-wide campaign of water-saving.

Note, however, that their understanding of the current "challenges" of unsustainable living is subject to change over time. As we will see in the later sections, they often face unforeseen conditions during the implementation phase. At such occasions, they reconsider their actions and roles for changing the contexts with a clearer understanding of the background causes of these challenges.

\subsection{Approaches Taken-To Unlock the "Web"}

Projects took actions combining some of the activities as follows to address these two-fold challenges of unsustainable living and the conditions.

\subsubsection{Visualisation of the Impacts of the Current Patterns of Living and Benefits of Alternatives}

Firstly, almost all the projects worked to take those living conditions or associated impacts which were not visible to the stakeholders, and make them visible. Once people have a clear vision of what they are doing currently, how much they pay and what impacts these behaviours will cause, they may have the chance to reconsider or even redirect some of their behaviours. Thus, visualisation works as the first step to create an alternative connection between people, resources or practices that may stabilise their living conditions with fewer negative impacts. One of the projects in Thailand, for instance, developed a database of the energy use in urban households and provided families with a home energy audit clarifying the status of energy use in comparison with their neighbours, with clear suggestions on no- or low-cost measures for energy saving. Another project in India launched "Food-Info-Marts" where urban food consumers purchase organic produce grown in the surrounding farm areas and also obtain knowledge about healthy diets. A third project in Ballina, Ireland (Box 3) measured household ecological footprints and worked with them to develop means of lowering their impacts, through storytelling.

Box 3. Case 3: Community Footprinting in Ballina, Ireland.

Working with small community groups in a small town in Ireland, this project managed to achieve reductions of $28 \%$ in recipients' ecological footprints. This was achieved through accurate footprinting so that recipients understood their environmental impact and storytelling, which included both short case studies developed by the participants themselves, and as well as slogans created through local competitions in schools to reinterpret technical messages. Through providing the necessary tools and placing the recipients at the centre of the project through the co-creation of footprint reduction activities and asking them to co-create messages to encourage others to join, the project was able to achieve high levels of engagement and maintain interest over the multi-year implementation time span. The project was rooted in what was tangible and interesting for the participants by focusing on transport, energy, water and waste. This participant-centred approach demonstrates the impact that can be achieved through co-development and small collective actions. 


\subsubsection{Introduction of Tools/Facilities That Enables People to Connect to "Elements" Differently}

Visualisation of the current patterns could be more supportive for people in creating alternative practices when specific suggestions or guidance follows, or when people can take part in collective actions for experimenting with alternative behaviours. Some projects introduced tools, equipment, or facilities that enable changes to the current patterns of behaviour that were visualised. Introduction of small tools and more extensive facilities were carried out on many projects. For instance, the project in Vietnam introduced information and guidance on water-saving measures to selected households in the city. Following that, the project also installed several simple tools supporting water-saving actions, such as water-saving taps in the pilot households. The tools made it easier for people to take concrete steps in changing their water-using behaviours. The project in Armenia is another case, where it introduced cheap tools to turn sunshine into energy, and provided other benefits for local living. Another project in Chile established two facilities utilising geothermal energy, namely, a firewood drier and a greenhouse producing leafy vegetables. These facilities brought together local farmers in the experimental production of firewood and vegetables.

Such actions have several effects. Physical tools work as the interface between individuals or families and those resources that can meet their needs. The tools provided in the aforementioned cases in Armenia and Vietnam enabled people to adopt cleaner ways of using water, food or energy, or even turn something they have wasted into a useful product. Information tools, on the other hand, connect people with different knowledge and resources through the facilitated exchange of information on, for instance, surplus food, available water or recyclable paper, and enable them to avoid waste, reduce costs and gain additional income.

\subsubsection{Setting up of Spaces for Collaboration and Co-Creation of Knowledge}

Furthermore, tools and facilities can be even more effective when they are managed in cooperation with local people and organisations. Tools or facilities can work for local people as a centre for knowledge creation through which they can share about their daily experiences, challenges or concerns, and find excellent opportunities. This then contributes to the development of capacity and aspiration of the local people in collectively creating alternative ways of living.

Projects set up a variety of spaces for collaboration and co-creation of knowledge. Some of them formed groups of participants who seek productive usages of physical tools or facilities. In contrast, others took advantage of the existing organisations of sites such as schools, kindergartens, offices or housewife groups, such as the Green Office project in Viet Nam (Box 4). They often provided training sessions to these groups or encouraged them to take collective action to make tangible changes in their particular contexts, such as the workplace. Some projects introduced physical (e.g., experimental fields) or virtual spaces (e.g., mobile apps) where people can meet and exchange their different needs, offers, skills and knowledge.

Box 4. Case 4: Upscale and Mainstream Green Office (GO) Lifestyles in Vietnam.

With Vietnam undergoing rapid urbanisation and economic growth, the country is seeing the emergence of a white-collar middle class. Faced with a deteriorating environment, many workers and companies are becoming increasingly interested in sustainability. In response to this, the Green Office project was established by AITVN under the One-Planet Network in order to develop green offices in key consumption areas such as energy, water, waste, paper and office equipment leading to reductions of $20 \%$ in CO2 emissions. To support this, a Green Office (GO) Lifestyle toolkit and GO Standards for a public audience were developed. The project was run in a total of ten offices across three cities-Hanoi, Ho Chi Minh City and Da Nang. Following implementation, the average emissions per capita was reduced by $8.9 \%$, with the highest reduction being $22.5 \%$. Over a thousand people were introduced to the Green Office approach, and the development of the toolkit and standards has ensured the sustainability of the project in the longer term. 
Combining these activities is useful in producing alternative sets of competence, materials and meanings. Competence here is not limited to one's ability to do something one is taught in the training workshop. It also includes the ability to create alternative connections between oneself with materials-such as water, sunlight, waste and food to bring out their values to sustain the living or improve the living conditions. It also covers the competence to communicate, negotiate, and collaborate with other people-family members, neighbours, colleagues, public or private organisations-in creating the local socioeconomic contexts where they can continuously engage in the creation of new values. Thus, these approaches were not just the replacement of the parts of the systems. The above methods of visualisation, introduction of tools and setting up of spaces for co-creation fostered the creation of alternative connections among the elements of the systems such as people, material and skills and created new competences and meanings.

\subsection{Learning by Doing-How Actors Grew through Moving forward the Innovations in the Making}

Even if a project addresses a definite challenge and identifies the practical approaches to address it, it is still not possible to create a perfect implementation plan which anticipates everything. Thus, it is crucial to understand at which opportunities the actors are urged to reconsider their actions, and how they are informed to review their activities or purposes.

\subsubsection{Learning Opportunities}

Projects were often urged to reconsider the contexts and change some of the planned actions.

- Difficulty in building relationships with partners and participants: Projects were able to smoothly build cooperative relationships with partners when they were already well aware of the necessity to change current living patterns. However, if this was not the case, projects found it hard to find participants and identify and build partnerships with the key organisations to collaborate with and gaining active participation of the local people.

- Compatibility of the knowledge, skills and tools with the local cultures or environments: Following the identification of key partners, the projects took further steps to organise participants and initiate training courses or introduce tools. At this stage, projects often had difficulty in delivering the knowledge and skills of the participants or supporting them in using the tools introduced. Sometimes projects discovered that the tools or knowledge they tried to apply are not useful in the local context.

- Unforeseen changes in the external conditions: For projects required to generate outcomes in only a few years, sudden changes in external conditions can be a severe challenge jeopardising plans. The activities in the project in Chile were delayed due to the changes in the local government during the early stages of the project. The project in Zimbabwe with farmers' organisations had to cancel some of the activities due to a drought, currency crisis and cholera outbreak.

\subsubsection{Reflections on Lessons Learned}

These challenges enabled them to review and modify their actions, partnerships and even the goals. They adjusted, for instance, the contents of the training programmes, types of tools and timings and locations of activities to fit the local contexts or unforeseen situation. Many of them carried out modifications more than once.

In some cases, the project team reconsiders the activities with a recognition that they need to take some additional measures to achieve their intended outcomes. The additional measures would be, for instance, the introduction of different tools or skills; the organisation of participants for growing their skills and motivation or the introduction of policies, infrastructure, or education programmes that would enable conditions for behaviour changes.

Such additional measures often required the project team to collaborate differently with partners. The case in Armenia shows how project partners, such as the local government and parents, shifted their 
ways to engage with the project from the potential beneficiaries into the collaborators. The water-saving project in Da Nang, Vietnam added new activities of the active learning programmes in collaboration with additional partners, namely schools and kindergartens. Likewise, a few projects engaged with policymakers to deliver policy recommendations out of their actions in search of more substantial support to ensure continued benefits after the completion of the project period. Moreover, participants of a few projects redesigned their group structures during the implementation period to make the best use of the enthusiasm or advanced skills of some of the key persons of the local society in growing the capacities and aspirations of the local participants such as farmers' clubs in Zimbabwe (Box 5). Enthusiastic or skilled "participants" become "trainers", "masters" or "leaders" in the later stage of the project implementation and play crucial roles in creating and spreading the skills they developed, marketing their products for securing their livelihoods and connecting with additional partners. Through these "additional" actions, participants developed their capacities and assumed more essential roles in causing the changes.

Box 5. Case 5: Farmers' Clubs in Zimbabwe.

The project in Zimbabwe formed farmers' groups and established experimental fields where the groups provided knowledge and skills for conservation agriculture, horticulture and small livestock production. From the previous implementation in other areas, the project team identified these means as measures for helping farmers mitigate their impacts on the natural environment and, at the same time, become resilient to external shocks such as flood and droughts, or an economic crisis. In addition to training on production, the project also covered nutrition, sanitation and health and marketing to strengthen farming households and communities in a holistic manner.

The project started amid the currency fluctuation that limited farmers' capacity to purchase necessary farm inputs. Participants saw that they could stabilise their household economy with small additional incomes from these activities. However, the project team and participants gave up one of their planned activities of establishing communal saving as it was challenging to develop and manage it stably due to continuous currency risk. Another unforeseen crisis hit the project when a cholera outbreak occurred in the region. During this crisis, participating farmers moved quickly to visit neighbouring areas to disseminate what they learned about health and sanitation as well as the importance of having stable livelihoods. Through these unforeseen events, the farmers grew their capacity to play a more significant role in the local society in creating resilient living conditions.

Unforeseen situations often hinder the smooth implementation of the project activities as planned. However, they also give them opportunities for the project teams and partners in reconsidering their roles in creating the alternative contexts of living and grow their competencies to more proactively move forward. Furthermore, with more proactive roles and competencies, project teams and partners gain deeper considerations of the purposes-what they are collaborating on, creating alternative contexts of living. Thus, ground-level transitions in the making does not mean that they continuously modify their activity plans toward the pre-determined goals. The purposes of the transitions or the visions of the desired future lifestyles or their contexts continue to evolve.

\section{Discussion and Conclusions}

Thus far, we have analysed some of the common points learned from the small- and micro-scale collaborative actions which the Sustainable Lifestyles and Education Programme of the One-Planet Network has collaborated on from 2016 to 2019. We have learned that the efforts to achieve sustainable lifestyles are, in a nutshell, collective actions of creating the contexts where local people can achieve more responsible and reliable living. Local initiatives have addressed a wide variety of locally specific challenges, namely, the increasing negative impacts associated with growing consumption, and unstable livelihoods and consumption. These two challenges are deeply entangled, as was shown from the above-cited cases 1 and 2. Thus, most of them needed to aim for responsible and reliable living at the same time. To this end, they visualised the current status of living and the associated impacts as illustrated in cases 2 and 3, introduced physical tools or facilities to better utilise the locally available resources in meeting the day-to-day needs (cases 1,2,4) and set up spaces for collaboration 
where local actors learn from each other (cases 1-5) to create alternative connections between human actors and material objects, or individuals and organisations. However, we have also seen that none of these collective actions went as planned despite detailed preparation. They faced difficulties in establishing partnerships (cases 1,4), applying knowledge and skills (cases 1,3) and unforeseen events caused by political and economic conditions or natural disasters (cases 1,5). Facing such challenges, local actors modified their plans. In doing so, they gained a deeper consideration of the drivers of their unsustainable conditions, what kind of alternatives they envision and what roles they can play in their efforts to achieve them. In other words, local actors co-create competencies and the meaning of (un)sustainable lifestyles in collaborative spaces.

The above lessons indicate that we would need to reconsider the meanings and conditions of systemic changes that enable sustainable lifestyles. Sustainable lifestyles at the local level will require changes to the systems enabling and constraining the local living contexts. However, such systemic changes are not realised only by replacing a few of the parts or elements to "make it work with less waste" or to "teach people to make a wise choice." We have seen that, for instance, visualisation of the negative impacts of living and introduction of the tools or facilities to enable people to reduce energy, water or waste may work when local actors play active roles in such visualisation or introduction/operation of the tools. The systems $[11,12,44]$ or entanglements $[15,16]$ where our lifestyles are situated is not about engineering elements of materials and tools that would potentially contribute to meeting our needs with "reduced negative impacts". They comprise materials and tools, knowledge and skills to utilise them and meanings or aspirations of people in creating positive relations with knowledge, skills, tools and materials. Likewise, systemic changes are not about replacing some of its parts but are the process where actors explore the potentials of alternative ways of living, and the roles they can play in pursuit of such alternatives. The transition to sustainable lifestyles is not a direct and one-time shift from current unsustainable patterns to pre-defined sustainable patterns. A change in lifestyles needs systemic changes which do not take place somewhere distant from individuals or groups of people but arise as the growth of skills, tools, intentions, competences and aspirations through the collective efforts in response to locally specific challenges. It is more of a collaborative and continuous exploration $[54-56,59,70]$ into the locally specific meaning of (un)sustainable living conditions and creation of competences that connect people and people or people and knowledge, skills, tools and materials in different ways.

With the above points in mind, we would also need to reconsider the ways in which governments, business and civil society can support or promote the shift in lifestyles. A broad range of policy measures and business models are already tested and are contributing to the uptake of more sustainable lifestyles. The business sector is, for example, providing information on the negative impacts associated with the production and use of specific goods and services so that consumers can make wiser choices or introduce products or services that enable consumers to meet their needs with fewer negative impacts. Governments are supporting such measures through, for instance, offering economic incentives, setting up standards of goods and services, criteria for information provision or providing certificates [71]. Such policies could potentially be more effective when they can encourage proactive interpretation and adaptation by local actors toward their collective efforts in addressing particular issues of the local living conditions. By way of an illustration, the business sector can set up a "laboratory" type of collaborative space together with local businesses or citizens' groups for developing and delivering innovative goods or services that reduce negative impacts and at the same time generating income opportunities for the local society [72,73]. By doing so, they do not only contribute to responsible and reliable living but also enlarge the prospects for further innovations driven by the local actors.

Moreover, we should also pay attention to the dynamic natures of innovations of lifestyles and living contexts in the making, instead of trying to make a one-time shift to the pre-determined goal. Monitoring and evaluation of the progress of activities "as planned" is necessary but not sufficient for supporting dynamic collaboration. Monitoring activities can be counter-productive when they are done to make sure the $100 \%$ achievements of the planned objectives, since they may kill the chances 
for the participants of learning from the reality to develop their competencies and to generate their own unique meaning of sustainable living. To support the exploration of the local actors, we-as governments, civil society actors or researchers-would need to accompany them in responding to unforeseen challenges and eventually creating their competencies for and meanings of sustainable living. Recently, Developmental Evaluation has gained traction with a similar line of thinking [74-76]. We would further need to elaborate such innovative ways of supporting the ground-level collaborative actions, taking account of the dynamics of the conditions of activities, roles of the stakeholders and the goals of the initiatives.

This paper aims to propose a deeper understanding of how people engage in the "systemic changes" of lifestyles, building on the research on lifestyles that focus on how lifestyles are entangled in the systems of provision comprising various elements. The work draws on the results of the work undertaken as part of the SLE Programme. The analysis is, therefore, post-hoc and was developed from discussions regarding the results and the commonalities that were found between projects that were very culturally and geographically diverse. This poses two specific limitations: (a) the analytical approach used by this paper was not integrated into the projects and the project implementers did not consider this specific approach when implementing their projects, and (b) the analysis here does not pay sufficient attention to the pathways of the projects and participants after their initial period. In order to deepen understanding of the transition to sustainable lifestyles and the ways in which stakeholders interact with each other and alter practices, it would be necessary to improve our ways of working with ground-level innovations, integrating this approach into project planning and collaborating for longer years. As the future development of the Global South will be critical to whether humanity is able to avoid the worst effects of climate change, a greater understanding of the means by which we can learn to live well within planetary boundaries will be needed.

More than 30 years have passed since international society recognised the necessity to shape more sustainable lifestyles. A multitude of trials for shifting lifestyles exist globally and aim for alternative ways of achieving wellbeing with fewer resources and energy, giving more and more insight into the need to and possibilities of shaping alternative ways of living. However, we need to bear in mind that the potentials of such trials are not limited to their achievements of pre-determined goals, such as reduced material or energy use, through the one-shot actions of tweaking one or two elements of lifestyles. Instead, they need to be fostered as inseparable steps of endless co-creation of new meanings of alternative ways of living and competence to realise them. We, thus, need to continue our exploration to better learning from and collaborating with these ground-level innovations.

Author Contributions: The concept and structure of this article was developed jointly by the authors. A.W. is the lead author, and developed the initial draft, to which S.G. added case studies. Final development of the paper was then conducted jointly by the authors. All authors have read and agreed to the published version of the manuscript.

Funding: The development of the paper is supported by the Policy Design and Evaluation to Ensure Sustainable Consumption and Production Patterns in Asian Region (PECoP-Asia) project funded by the Environmental Research and Technology Development Fund, Japan.

Acknowledgments: The authors are thankful for the implementers of the initiatives under the Sustainable Lifestyles and Education Programme of the One-Planet Network (10-Year Framework of Programmes on Sustainable Consumption and Production Patterns).

Conflicts of Interest: The authors have been involved in the processes of evaluating and supporting the 24 projects under the Sustainable Lifestyles and Education Programme and the selection of case studies cited in the paper. 


\section{Appendix A}

Table A1. Projects selected under the Open Call for Projects and Policies and Instruments Studied.

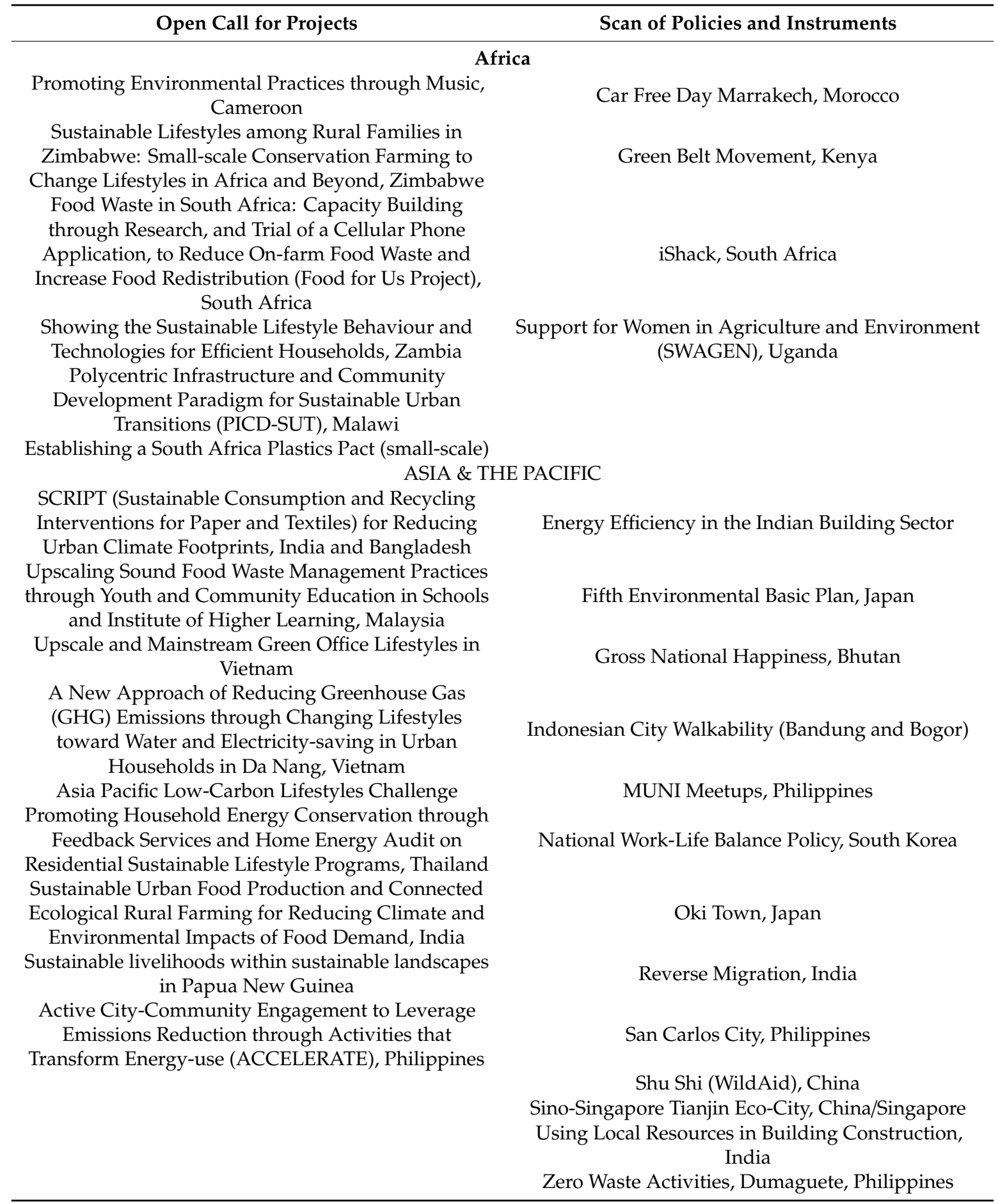


Table A1. Cont.

\begin{tabular}{|c|c|}
\hline Open Call for Projects & Scan of Policies and Instruments \\
\hline \multicolumn{2}{|c|}{ North and Latin America and The Caribbean } \\
\hline Education for Sustainability and Consumption, Brazil & \multirow[t]{5}{*}{ Costa Rica's Biodiversity Law } \\
\hline Direct Use of Geothermal Energy for the Promotion of & \\
\hline Sustainable Production Model in Rural Areas in Chile: & \\
\hline $\begin{array}{l}\text { Implementation of Pilot Projects in Firewood Drying } \\
\text { and Greenhouse for Agricultural Farming, Chile }\end{array}$ & \\
\hline How Emerging Urban Youth can be an Engine for & \\
\hline $\begin{array}{c}\text { More Low-carbon, Sustainable Lifestyles: Beginning } \\
\text { in Bogota, Colombia }\end{array}$ & Montréal's Multi-Model Transportation Mix, Canada \\
\hline \multicolumn{2}{|l|}{$\begin{array}{l}\text { Better by Design-Replicating Promising Practices, } \\
\text { Tools and Methodologies to Support and Enable }\end{array}$} \\
\hline Companies in Latin America to Improve the & Patagonia, United States \\
\hline \multicolumn{2}{|l|}{$\begin{array}{l}\text { Sustainability of their Food and Beverage Products, } \\
\text { Peru, Nicaragua and Honduras }\end{array}$} \\
\hline $\begin{array}{l}\text { Sustainable Lifestyles in the Workplace, Morocco \& } \\
\text { Colombia }\end{array}$ & Rizoma Field School, Uruguay \\
\hline Solar energy for improved rural livelihoods in Peru & Sidewalk Toronto, Canada \\
\hline \multicolumn{2}{|l|}{$\begin{array}{c}\text { The recovery of traditional rice and wheat cultivation } \\
\text { for food sovereignty in integrated agroecological } \\
\text { production systems, Colombia }\end{array}$} \\
\hline \multicolumn{2}{|l|}{ Europe } \\
\hline $\begin{array}{c}\text { Solar Energy for Low-Carbon Sustainable Lifestyles } \\
\text { in Solak, Aygavan and Malishka Rural Communities } \\
\text { of Armenia }\end{array}$ & Ballina Eco District, Ireland \\
\hline \multirow[t]{7}{*}{$\begin{array}{c}\text { Encouraging young specialists to power the agri-food } \\
\text { value chains and building sustainable business } \\
\text { models, Armenia and Chile }\end{array}$} & $\begin{array}{l}\text { BioSzentandás, Hungary } \\
\text { Incredible Edible Todmorden, UK }\end{array}$ \\
\hline & $\begin{array}{l}\text { London Bans Junk Food Ads on the Transport for } \\
\text { London Network, UK }\end{array}$ \\
\hline & National Consumption Strategy, Sweden \\
\hline & National Loneliness Policy, UK \\
\hline & Nudge in a Green Direction, Belgium \\
\hline & Ruby Cup, UK \\
\hline & Sieben Linden Ecovillage, Germany \\
\hline
\end{tabular}

\section{References}

1. Institute for Global Environmental Strategies. The 10YFP Programme on Sustainable Lifestyles and Education; Institute for Global Environmental Strategies: Hayama, Japan, 2017; pp. 1-5.

2. Del Pino, S.P.; Metzger, E.; Drew, D.; Moss, K. The Elephant in the Boardroom: Why Unchecked Consumption Is Not an Option in Tomorrow's Markets; World Resources Institute: Washington, DC, USA, 2017; pp. 1-36.

3. Scott, K. A literature review on sustainable lifestyles and recommendations for further research. Stock. Environ. Inst. Proj. Rep. 2009, 42. [CrossRef]

4. Lorek, S.; Spangenberg, J.H. Sustainable consumption within a sustainable economy-Beyond green growth and green economies. J. Clean. Prod. 2014, 63, 33-44. [CrossRef]

5. Meroni, A.; Corubolo, M.; Piredda, F.; Jegou, F.; Schäfer, B.; Salvador, G. Exploring Pathways towards Sustainable Lifestyles. In Proceedings of the Global Research Forum on Sustainable Consumption and Production Workshop, Rio de Janeiro, Brasil, 13-15 June 2012; pp. 1-15.

6. Moloney, S.; Strengers, Y. "Going Green"? The limitations of behaviour change programs as a policy response to escalating resource consumption. Environ. Policy Gov. 2014, 24, 94-107. [CrossRef]

7. Gatersleben, B.; White, E.; Abrahamse, W.; Jackson, T.; Uzzell, D. Values and sustainable lifestyles. Arch. Sci. Rev. 2010, 53, 37-50. [CrossRef]

8. Barr, S.; Shaw, G.; Coles, T. Sustainable lifestyles: Sites, practices, and policy. Environ. Plan. A 2011, 43, 3011-3029. [CrossRef] 
9. Rakic, M.; Rakic, B. Sustainable lifestyle marketing of individuals: The base of sustainability. Amfiteatru Econ. 2015, 17, 891-908.

10. Cohen, S. Understanding the Sustainable Lifestyle. Available online: https://www.europeanfinancialreview. com/understanding-the-sustainable-lifestyle/ (accessed on 8 September 2020).

11. Evans, D.; Abrahamse, W. Beyond rhetoric: The possibilities of and for "sustainable lifestyles". Environ. Polit. 2009, 18, 486-502. [CrossRef]

12. Spaargaren, G.; Oosterveer, P. Life(style) Politics for Sustainable Consumption Analysing the Role of Citizen-Consumers in Global Environmental Change. In Proceedings of the European-American workshop on "Climate Change Mitigation: Considering Lifestyle Options in Europe and the US", Berkeley, CA, USA, 1 May 2009; pp. 1-20.

13. Spaargaren, G. Theories of practices: Agency, technology, and culture. Exploring the relevance of practice theories for the governance of sustainable consumption practices in the new world-order. Glob. Environ. Chang. 2011, 21, 813-822. [CrossRef]

14. Welch, D.; Warde, A. Theories of practice and sustainable consumption. Handb. Res. Sustain. Consum. 2014, 84-100. [CrossRef]

15. Dijk, M.; Backhaus, J.; Wieser, H.; Kemp, R. Policies tackling the "web of constraints" on resource efficient practices: The case of mobility. Sustain. Sci. Pract. Policy 2019, 15, 62-81. [CrossRef]

16. Backhaus, J.; Wieser, H.; Kemp, R. Disentangling practices, carriers, and production-consumption. In Putting Sustainability into Practice: Applications and Advances in Research on Sustainable Consumption; Kennedy, E.H., Cohen, M.J., Krogman, N.T., Eds.; Edward Elgar Publishing: Cheltenham, UK, 2015; pp. 109-133. ISBN 9781784710590.

17. United Nations Environment Programme. Visions for Change Recommendations for Effective Policies on Sustainable Lifestyles; United Nations Environment Programme: Paris, France, 2011.

18. United Nations Environment Programme. Decoupling Natural Resource Use and Environmental Impacts from Economic Growth Using Less Resources and Reducing the Environmental Impact; United Nations Environment Programme: Paris, France, 2011; ISBN 9789280731675.

19. Jackson, T. The challenge of sustainable lifestyles. In 2008 State of the World; Worldwatch: Washington, DC, USA, 2008; pp. 45-60.

20. Spaargaren, G.; Vliet, B. Van Lifestyles, consumption and the environment: The ecological modernization of domestic consumption. Environ. Polit. 2000, 9, 50-76. [CrossRef]

21. Evans, D.; Jackson, T. Towards a Sociology of Sustainable Lifestyles; Resolve Working Paper; University of Surrey: Guildford, UK, 2007; pp. 1-24.

22. Holt, D.B. Poststructuralist lifestyle analysis: Conceptualizing the social patterning of consumption in postmodernity. J. Consum. Res. 1997, 23, 326. [CrossRef]

23. Bourdieu, P. Distinction-A Social Critique of the Judgement of Taste; Harvard University Press: Cambridge, MA, USA, 1984; ISBN 0674212770.

24. Slater, D. Consumer Culture and Modernity; Polity Press: Cambridge, UK, 1997.

25. Giddens, A. Modernity and Self-Identity Self and Society in the Late Modern Age; Stanford University Press: Stanford, CA, USA, 1991.

26. Roberts, K. Leisure in Contemporary Society; CABI Publishing: Wallingford, UK, 1999.

27. Veal, A.J. Leisure, Culture and LifestyleLoisir, culture et mode de vieDiversión, cultura y estilo de vida. Loisir Soc. 2012, 24, 359. [CrossRef]

28. Petev, I.D. The association of social class and lifestyles: Persistence in American sociability, 1974 to 2010. Am. Sociol. Rev. 2013, 78, 633-661. [CrossRef]

29. Tomlinson, M. Lifestyle and social class. Eur. Sociol. Rev. 2003, 19, 97-111. [CrossRef]

30. Christiansen, C.H.; Matuska, K.M. Lifestyle balance: A review of concepts and research. J. Occup. Sci. 2006, 13, 49-61. [CrossRef]

31. Tabish, S.A. Lifestyle diseases: Consequences, characteristics, causes and control. Cardiol. Curr. Res. 2017, 9, 00326. [CrossRef]

32. Lawson, R.; Todd, S. Sumer lifestyles: A social stratification perspective. Mark. Theory 2002, 2, $295-307$. [CrossRef]

33. Keister, L.A.; Benton, R.; Moody, J. Lifestyles through expenditures: A case-based approach to saving. Sociol. Sci. 2016, 3, 650-684. [CrossRef] 
34. Sathish, S.; Rajamohan, A. Consumer behaviour and lifestyle marketing. Int. J. Mark. Financ. Serv. Manag. Res. 2012, 1, 152-166.

35. Terlau, W.; Hirsch, D. SUSTAINABLE consumption and the attitude-behaviour-gap phenomenon-causes and measurements towards a sustainable development. J. Food Syst. Dyn. 2015, 6, 159-174.

36. Vermeir, I.; Verbeke, W. Sustainable food consumption: Exploring the consumer "attitude-behavioral intention" gap. J. Agric. Environ. Ethics 2006, 19, 169-194. [CrossRef]

37. Sniehotta, F.F. Bridging the intention-behaviour gap: Planning, self-efficacy, and action control in the adoption and maintenance of physical exercise. Psychol. Health 2007, 20, 143-160. [CrossRef]

38. Carrington, M.J.; Neville, B.A.; Whitwell, G.J. Lost in translation: Exploring the ethical consumer intention-behavior gap. J. Bus. Res. 2014, 67, 2759-2767. [CrossRef]

39. Boulstridge, E.; Carrigan, M. Do consumers really care about corporate responsibility? Highlighting the attitude-behaviour gap. J. Commun. Manag. 2000, 4, 355-368. [CrossRef]

40. Shaw, D.; McMaster, R.; Newholm, T. Care and commitment in ethical consumption: An exploration of the 'attitude-behaviour gap'. J. Bus. Ethics 2016, 136, 251-265. [CrossRef]

41. Welch, D. Behaviour change and theories of practice: Contributions, limitations and developments. Soc. Bus. 2017, 7, 241-261. [CrossRef]

42. Shove, E. Beyond ABC: Climate change policy and theories of social change. Environ. Plan. A 2010, 42, 1273-1285. [CrossRef]

43. Schatzki, T.R.; Knorr-Cetina, K.; von Savigny, E. The Practice Turn in Contemporary Theory; Routledge: London, UK, 2001; ISBN 0415228131.

44. Reckwitz, A. Toward a theory of social practices: A development in culturalist theorizing. Eur. J. Soc. Theory 2002, 5, 243-263. [CrossRef]

45. Warde, A. Consumption and theories of practice. J. Consum. Cult. 2005, 5, 131-153. [CrossRef]

46. Ropke, I. Theories of practice-New inspiration for ecological economic studies on consumption. Ecol. Econ. 2009, 68, 2490-2497. [CrossRef]

47. Shove, E. Stuff, image and skill: Towards an integrative theory of practice. Designing and Consuming Objects, Practices and Processes Workshop; Durham University: Durham, UK, 11 January 2005.

48. Sahakian, M.; Wilhite, H. Making practice theory practicable: Towards more sustainable forms of consumption. J. Consum. Cult. 2014, 14, 25-44. [CrossRef]

49. Shove, E.; Walker, G. Governing transitions in the sustainability of everyday life. Res. Policy 2010, 39, 471-476. [CrossRef]

50. Hargreaves, T.; Longhurst, N.; Seyfang, G. Understanding Sustainability Innovations: Points of Intersection between the Multi-Level Perspective and Social Practice Theory; 3S Working Paper 2012-03; University of East Anglia: Norwich, UK, 2012; pp. 1-25.

51. Burningham, K.; Venn, S. Are lifecourse transitions opportunities for moving to more sustainable consumption? J. Consum. Cult. 2017, 20, 102-121. [CrossRef]

52. Lorenzen, J.A. Going Green: The Process of Lifestyle Change; Lorenzen, A.L., Ed.; Wiley Stable: Hoboken, NJ, USA, 2012; Volume 27, pp. 94-116. Available online: http://www.jstor.org/stable/41330915 (accessed on 8 September 2020).

53. Spangenberg, J.H.; Lorek, S. Sufficiency and consumer behaviour: From theory to policy. Energy Policy 2019, 129, 1070-1079. [CrossRef]

54. Anantharman, M. Critical sustainable consumption: A research agenda. J. Environ. Stud. Sci. 2018, 8, 553-561. [CrossRef]

55. O’Neill, K.J.; Clear, A.K.; Friday, A.; Hazas, M. “Fractures" in food practices: Exploring transitions towards sustainable food. Agric. Hum. Values 2019, 36, 225-239. [CrossRef]

56. Seyfang, G.; Haxeltine, A.; Hargreaves, T.; Longhurst, N. Energy and Communities in Transition-towards a New Research Agenda on Agency and Civil Society in Sustainability Transitions; Working Paper; Center for Social Economic Research on the Global Environment, University of East Anglia: Norwich, UK, 2010; pp. 1-21.

57. Seyfang, G.; Longhurst, N. Desperately seeking niches: Grassroots innovations and niche development in the community currency field. Glob. Environ. Chang. 2013, 23, 881-891. [CrossRef]

58. Smith, A.; Raven, R. What is protective space? Reconsidering niches in transitions to sustainability. Res. Policy 2012, 41, 1025-1036. [CrossRef] 
59. Hagbert, P.; Bradley, K. Transitions on the home front: A story of sustainable living beyond eco-efficiency. Energy Res. Soc. Sci. 2017, 31, 240-248. [CrossRef]

60. Marchand, A.; Walker, S. Insights for sustainable lifestyles and communities: Ecocitizens as key informants. Proceedings of International Conference on Adequate \& Affordable Housing for All, Toronto, ON, Canada, June 24-27 2004; pp. 1-7.

61. Miller, E.; Bentley, K. Leading a sustainable lifestyle in a 'non-sustainable world': Reflections from Australian eco-village and suburban residents. J. Educ. Sustain. Dev. 2012, 6, 139-149. [CrossRef]

62. Anantharaman, M. When Do Consumers Become Citizens? In Proceedings of the Global Research Forum on Sustainable Consumption and Production Working paper, Rio Janiero, Brazil, 13-15 June 2012; pp. 1-18.

63. Kennedy, E.H. Rethinking ecological citizenship: The role of neighbourhood networks in cultural change. Environ. Polit. 2011, 20, 843-860. [CrossRef]

64. Wolfram, M. Cities shaping grassroots niches for sustainability transitions: Conceptual reflections and an exploratory case study. J. Clean. Prod. 2016. [CrossRef]

65. Bulkeley, H.; Castan Broto, V.; Maassen, A. Low-carbon transitions and the reconfiguration of urban infrastructure. Urban Stud. 2014, 51, 1471-1486. [CrossRef]

66. Baker, S.; Mehmood, A. Social innovation and the governance of sustainable places. Local Environ. 2015, 20, 321-334. [CrossRef]

67. Rogers, Z.; Bragg, E. The power of connection: Sustainable lifestyles and sense of place. Ecopsychology 2012, 4, 307-318. [CrossRef]

68. Winkler, B.; Maier, A.; Lewandowski, I. Urban gardening in Germany: Cultivating a sustainable lifestyle for the societal transition to a bioeconomy. Sustainability 2019, 11, 801. [CrossRef]

69. Wieser, H.; Backhaus, J.; Kemp, R. Exploring Consistencies and Spillovers across Food Shopping Practices. In Proceedings of the 5th International Sustainability Transitions Conference, Utrecht, The Netherlands, 26-29 August 2014; pp. 1-26.

70. Chilvers, J.; Longhurst, N. Participation in transition(s): Reconceiving public engagements in energy transitions as co-produced, emergent and diverse. J. Environ. Policy Plan. 2016, 18, 585-607. [CrossRef]

71. Gilby, S.; Mao, C.; Koide, R.; Watabe, A.; Hengesbaugh, M.; Appleby, D.; Nugroho, S.B.; Kamei, M.; Liu, C.; Chepelianskaia, O.; et al. Sustainable Lifestyles Policy and Practice: Challenges and Way Forward; Institute for Global Environmental Strategies: Hayama, Japan, 2019.

72. Tellioğlu, H.; Wagner, M.; Habiger, M.; Mikusch, G. Living Labs Reconsidered for Community Building and Maintenance. In Proceedings of the 9th International Conference on Communities \& Technologies-Transforming Communities, Vienna, Austria, 3-7 June 2019; pp. 154-159.

73. Almirall, E. Living Labs: Arbiters of mid-and ground-level innovation. Technol. Anal. Strateg. Manag. 2011, 1, 87-102. [CrossRef]

74. Gamble, J.A.A. A Developmental Evaluation Primer; The J.W. McConnell Family Foundation: Montreal, QC, Canada, 2008.

75. Patton, M.Q. Developmental Evaluation. Applying Complexity Concepts to Enhance Innovation and Use; The Guilford Press: New York, NY, USA, 2010.

76. Dozois, E.; Langlois, M.; Blanchet-Cohen, N. A Practitioner's Guide to Developmental Evaluation; The J.W. McConnell Family Foundation and the International Institute for Child Rights and Development: Montreal, QC, Canada, 2010.

(C) 2020 by the authors. Licensee MDPI, Basel, Switzerland. This article is an open access article distributed under the terms and conditions of the Creative Commons Attribution (CC BY) license (http://creativecommons.org/licenses/by/4.0/). 